\title{
Nonfunctioning islet cell pancreatic cancer
}

\author{
DAVID D. PERKINS, DO \\ JACK F. MEEKER, DO
}

\begin{abstract}
Nonfunctioning islet cell
tumors are rarer than functioning neuroendocrine pancreatic tumors.
\end{abstract} Although they share certain characteristics with functioning tumors, they do not show clinical evidence of hormonal secretion. Their symptoms usually arise as a result of the effect of the mass, jaundice, weight loss, and malaise. They are more likely to be malignant than functioning tumors. They are slow growing, however, and their size and malignancy do not preclude long survival. For these reasons they warrant aggressive surgical intervention.

Neuroendocrine tumors of the pancreas are rare. Estimates suggest that tumors in the pancreatic islet cells occur in fewer than 1 in 100,000 persons. ${ }^{1}$ Most of these tumors are functioning, that is, they are associated with hypersecretion of a variety of hormones and cause clinically recognizable syndromes. These include insulinomas, gastrinomas, and other tumors that secrete ACTH, glucagon, catecholamines, calcitonin, somatostatin, or other peptides. ${ }^{2}$

Nonfunctioning islet cell tumors that fail to show clinical evidence of hormone overproduction are even less common. The proportion of islet cell tumors that are nonfunctioning varies from study to study. Howard and coworkers ${ }^{3}$ in 1950 found that $41 \%$ of 398 published cases of islet cell tumor were nonfunctioning. More recently, nonfunctioning tumors constituted $15 \%$ of 168 cases of islet cell tumor at the Mayo Clinic from 1960 through $1978^{1}$ and $33 \%$ of 33 cases of islet cell carcinomas at Lahey Clinic from 1963 to $1984 .{ }^{4}$

Although these nonfunctioning tumors are uncommon, their recognition is important because they have many characteristics that differ from those of functioning islet cell tumors and their outlook is different as well. ${ }^{5-7}$

\section{Report of case}

A 63-year-old man was admitted to Garden City Hospital with the diagnosis of probable pancreatic carcinoma discovered incidentally. Three years prior to admission, the patient was found to be hyperglycemic during a laboratory study included in an insurance company's required physical examination. At that time, he was placed on Diabinese (chlorpropamide) therapy. During the ensuing period, he denied having any abdominal symptoms. A few weeks before admission, a routine blood study demonstrated a "low blood count." Further workup to determine the cause of anemia included an ultrasound study of the pancreas as well as a computed tomography scan of the abdomen with and without contrast. These studies revealed an enlargement of the tail of the pancreas with associated calcification. A needle biopsy was attempted on March 2,1987. The biopsy needle apparently was deflected as a result of the firmness of the mass in the tail of the pancreas. Therefore, it was unable to penetrate the mass to obtain a specimen.

The patient denied having any loss of appetite, weight loss, epigastric pain, jaundice, fatigue, or malaise. His prescribed medications included Micronase (glyburide) tablets ( $5 \mathrm{mg}$ every morning and $2.5 \mathrm{mg}$ every evening).

On physical examination, there was no evidence of jaundice or scleral icterus. His abdomen was soft and nontender with good bowel sounds. Palpation revealed no epigastric mass nor organ enlargement. There was no rebound, guarding, or rigidity. Findings of the rectal examination were essentially normal. Laboratory values were within normal limits except for a slightly elevated random blood glucose level $194 \mathrm{mg} / \mathrm{dL}$ ).

On March 17, 1987, the patient underwent an $80 \%$ distal pancreatectomy with splenectomy. A large, multilobulated, semicystic mass occupied the body and tail of the pancreas. The mass was extremely hard, and, in some areas, lobulated and cystic. The mass measured $8 \mathrm{~cm} \times 15 \mathrm{~cm}$. It appeared to involve only the tissues of the transverse mesocolon by contiguity.

The patient's hospital course was uncomplicated, and he was discharged on the 6 th postoperative day. Blood glucose values ranged from 150 to $300 \mathrm{mg} / \mathrm{dL}$. As of this publication, the patient continues to do well with no evidence of recurrence or metastatic disease.

The pathology department reported that the operative specimen was islet cell tumor with vascular invasion, probably malignant.

\section{Discussion}

In a series of surgically documented cases of islet cell tumor at the Mayo Clinic from 1960 through $1978,{ }^{1}$ insulinoma was the most common $(60 \%)$, 
then gastrinoma (18\%), followed by nonfunctioning tumors $(15 \%)$. The remainder $(7 \%)$ secreted various hormones. The Lahey Clinic series ${ }^{4}$ of 33 cases included $33 \%$ insulinomas, $33 \%$ nonfunctioning tumors, $30 \%$ gastrinomas, then $3 \%$ glucagonoma. It may be that the percentage of islet cell tumors now considered as nonfunctioning will decrease as newer methods for detecting hormones are developed. $^{1}$

Most nonfunctioning islet cell tumors are solitary,,$^{1,4,5}$ and they usually are solid. ${ }^{1}$ The size varies from $1 \mathrm{~cm}$ to as large as $30 \times 15 \mathrm{~cm}$. In most pancreatic islet cell tumors, the main site of origin is the head of the pancreas, ${ }^{1,4,5}$ followed by the tail ${ }^{1}$ or the body. ${ }^{4,5}$ Some tumors, as in the case reported here, arise from the body and tail or head and body. ${ }^{1}$ In the Lahey Clinic series, ${ }^{4}$ the tumors all arose from one pancreatic parenchymal focus.

Nonfunctioning islet cell tumors usually are accompanied by symptoms that are different from those accompanying functioning tumors, because symptoms with the former are not from hormonal production but from mass effect, local invasion, or metastasis. The presenting signs and symptoms usually include pain, jaundice, a palpable epigastric mass, malaise, or weight loss. ${ }^{1,4,5}$

Nonfunctioning islet cell tumors are more likely than functioning islet cell tumors to be malignant. The incidence of malignancy was $82 \%,{ }^{4} 82 \%,{ }^{5}$ and $92 \%^{1}$ in three recent series. Cytologic characteristics are not helpful in distinguishing benign from malignant tumors. ${ }^{1}$ Malignancy usually becomes evident through metastasis to other organs such as the liver.

Treatment consists mainly of surgery. An aggressive approach is advised even in large tumors or in the presence of metastasis since many patients experience prolonged survival under these circumstances. ${ }^{1,4-6}$ Survival is better in nonfunctioning than in functioning islet cell tumors. For example, for nonfunctioning islet cell tumors, Broder and Carter $^{7}$ reported median survival 9 months longer and Cubilla and Hajdu ${ }^{8}$ reported mean survivals 1.5 years longer than for functioning islet cell cancers.

Adjunctive chemotherapy has been helpful in patients with metastatic islet cell tumors. Streptozotocin, a broad-spectrum antibiotic that inhibits synthesis of DNA, is widely used. In one study, $64 \%$ of patients with nonfunctioning islet cell tumors responded to streptozotocin. ${ }^{9}$ More recently, streptozotocin has been used with 5 -fluorouracil for islet cell malignancies. Moertel and associates ${ }^{10}$ re- ported achieving somewhat better results with the combination than with streptozotocin alone.

Nonfunctioning islet cell tumors grow slowly and malignancy may go undetected, so patients may return years after surgery with recurrence or metastasis. Therefore, patients should be followed up for a long time. ${ }^{4}$

1. Kent RB III, Van Heerden JA, Weiland LH: Nonfunctioning islet cell tumors. Ann Surg 1981;193:186-190.

2. Friesen SR: Tumors of the endocrine pancreas. $N$ Engl $J$ Med 1982;306:580-590.

3. Howard JM, Moss NH, Rhoads JE: Hyperinsulinism and islet cell tumors of the pancreas with 398 recorded tumors. Int Abstr Surg 1950;90:417-455.

4. Dial PF, Braasch JW, Rossi RL, et al: Management of nonfunctioning islet cell tumors of the pancreas. surg Clin North Am 1985;65:291-299.

5. Eckhauser FE, Cheung PS, Vinik AI, et al: Nonfunctioning malignant neuroendocrine tumors of the pancreas. Surgery 1986;100:978988.

6. Sandrolini JA, Polcyn BM: Giant nonfunctioning islet cell tumor: Survival after pancreaticoduodenectomy. Am J Surg 1968;115:702-704.

7. Broder LE, Carter SK: Pancreatic islet cell carcinoma. I. Clinical features of 52 patients. Ann Intern Med 1973;115:101-107.

8. Cubilla AL, Hajdu SI: Islet cell carcinoma of the pancreas. Arch Pathol Lab Med 1975;99:204-207.

9. Broder LE, Carter SK: Pancreatic islet cell carcinoma. II. Results of therapy with streptozotocin in 52 patients. Ann Intern Med 1973;79:108118.

10. Moertel CG, Hanley JA, Johnson LA: Streptozotocin alone compared with streptozotocin plus fluorouracil in the treatment of advanced isletcell carcinoma. $N$ Engl J Med 1980;303:1189-1194.

From Garden City Hospital, Garden City, Mich.

Reprint requests to Dr Perkins, Garden City Hospital, 6245 N Inkster Rd, Garden City, MI 48135. 